\title{
Um Estado novo-desenvolvimentista na América Latina?
}

\author{
Luiz Carlos Bresser-Pereira * \\ Daniela Theuer **
}

\begin{abstract}
Resumo
A América Latina foi, provavelmente, a região que mais sofreu nos anos neoliberais, porque era inclusive onde as reformas e políticas respectivas foram levadas mais adiante. Por essa razão, foi também a região em que os anos neoliberais primeiro chegaram ao fim. Desde a década de 1990, líderes políticos de esquerda e economicamente nacionalistas começaram a ganhar as eleições. Por sua vez, uma nova escola de pensamento econômico baseada em uma nova "macroeconomia estruturalista do desenvolvimento" está em discussão e as "Dez Teses sobre o Novo Desenvolvimentismo" são hoje uma alternativa ao consenso de Washington. Significa que o Estado Desenvolvimentista está de volta? É muito cedo para afirmar isso, não só porque ideias e políticas raramente coincidem, mas também porque o aumento nos preços das commodities está ameaçando a industrialização na região.
\end{abstract}

Palavras-chave: Desenvolvimentismo; Estado desenvolvimentista; Ortodoxia liberal.

\section{Abstract}

\section{A new developmentalist state in Latin America?}

Latin America was probably the region that suffered most in the neoliberal years, because it was also the region where the respective reforms and policies were taken the furthest. For this reason, it was also the region where the neoliberal years first came to an end. In the late 1990s, left wing and economic nationalist political leaders started winning elections. However, a new economic school of thought based on a new concept of "structuralist development macroeconomics" has been under discussion, and the Ten Theses on New Developmentalism are today an alternative to the Washington Consensus. Does this mean that the developmentalist state has returned? It is too soon to say, not only because ideas and politics seldom match, but also because the rise in commodity prices is threatening industrialization in the region.

Keywords: Developmentalism; Developmentalist state; Liberal orthodoxy.

JEL O01, O11, O54.

\section{Introdução}

O discurso neoliberal que predominou no Norte desde 1980 apresentou duas alternativas ortodoxas para o Estado nos países em desenvolvimento: liberal ou populista. Com tal retórica, ele estava sugerindo serem o desenvolvimentismo e o Estado populista a mesma coisa e que o Estado liberal é a forma ideal do Estado

\footnotetext{
*Professor emérito da Fundação Getúlio Vargas (FGV), São Paulo, SP, Brasil. E-mail: bresserpereira@ gmail.com

** Professora visitante da Universidade Federal do ABC (UFABC), Santo André, SP, Brasil. E-mail: daniela theuer@gmail.com.
} 
- a única que pode assegurar o crescimento com estabilidade e justiça social. Esse discurso ideológico foi rejeitado pelos fatos. Após o consenso de Washington, políticas neoliberais foram implantadas em praticamente todos os países latino-americanos, enquanto os países asiáticos resistiram à nova hegemonia. Os resultados não foram surpreendentes. As economias latino-americanas cresceram a taxas mais baixas do que quando adotavam uma estratégia desenvolvimentista e foram superadas por países asiáticos que seguiram seu caminho novo-desenvolvimentista. Enquanto na América Latina a instabilidade financeira e a desigualdade aumentaram, nos países asiáticos os níveis de desigualdade não pioraram e a perda estabilidade financeira ocorreu, mas de forma limitada.

Diante do fracasso das políticas neoliberais, políticos nacionalistas e de esquerda foram eleitos e os novos governos vêm tentando construir Estados desenvolvimentistas. Isso envolveu a reestatização de algumas empresas monopolistas, geralmente empresas de serviços públicos e empresas de petróleo e de mineração onde as rendas ricardianas são grandes, mas o que é, afinal, um Estado desenvolvimentista? Será essa forma de Estado a melhor alternativa para países que querem realizar o alcançamento (catching up)? Será esse um caminho para um Estado social ou do bem-estar? Estará o Estado desenvolvimentista de volta na América Latina? Para que a resposta à última pergunta seja positiva, é necessário observar se os citados países estejam tentando construir uma coalizão de classes desenvolvimentista e procurando formular e implementar uma estratégia nacional de desenvolvimento: o novo desenvolvimentismo. As questões apresentadas serão discutidas neste artigo.

A análise aqui apresentada baseia-se em três pressupostos: Primeiro: o Estado tende a assumir duas formas alternativas em países em desenvolvimento: pode ser ou um Estado liberal ou um Estado desenvolvimentista. Segundo: o Estado desenvolvimentista é hoje diferente do que era nos anos 1950 a 1970: compete com outros países no quadro da globalização, aproveita melhor um mercado interno capitalista, é democrático e deve ser social ou inclusivo, por isso é ou precisa ser um Estado novo- desenvolvimentista. E, terceiro: na América Latina, a Nova Esquerda Desenvolvimentista é uma esquerda reformista cujo objetivo não é o socialismo, mas um Estado do bem-estar social. Para conduzir o argumento e a análise, é preciso primeiro definir o que se entende por liberalismo e desenvolvimentismo antigo e novo e o respectivo papel do Estado em cada uma dessas ideologias. Em seguida, analisar as políticas econômicas e sociais que estão sendo adotadas, avaliando-se até que ponto elas sinalizam (ou não) uma mudança para o Estado novo-desenvolvimentista e social. 


\section{Algumas definições}

Quando se fala aqui em um Estado novo-desenvolvimentista, trata-se de opô-lo a duas outras formas de Estado: por um lado, o Estado liberal e, por outro, o antigo Estado desenvolvimentista ou nacional-desenvolvimentista. O Estado liberal é o sistema político do liberalismo econômico (ou do que é hoje o neoliberalismo): é o Estado mínimo ou que busca ser mínimo, o Estado que apenas protege os direitos civis e assegura o cumprimento dos contratos. Este Estado, segundo o liberalismo econômico, não deve interferir na economia, porque o mercado supostamente é uma ferramenta mais eficaz e desejável de alocação de recursos e desenvolvimento de uma sociedade. Segundo o liberalismo político, seria a única forma de governo compatível com a democracia liberal. Na Arábia e na América Latina, todavia, o Estado liberal apresentou-se tradicionalmente como um Estado autoritário antes de o país se industrializar e, depois, teve tendência a ser uma democracia schumpeteriana ou de elites.

O Estado nacional-desenvolvimentista, em oposição ao liberal, é um Estado que intervém diretamente na economia com a finalidade de promover o desenvolvimento econômico. É importante ressaltar que seu nacionalismo, como interpretado aqui, é apenas econômico, não tem qualquer componente étnico. Assim como o Estado liberal, o Estado desenvolvimentista foi originalmente um regime político autoritário, que tendeu a se tornar democrático à medida que foi bem sucedido na promoção da revolução nacional e industrial em cada país. O Estado desenvolvimentista é nacionalista no plano econômico porque pressupõe a existência de dependência econômica em relação aos países ricos - uma subordinação que entende ser um obstáculo maior ao crescimento econômico, por levar os países em desenvolvimento a aceitarem políticas e reformas que não atendem a seus interesses nacionais. Por essa razão, o desenvolvimentismo contém um componente antiimperialista. Enquanto os países ricos usam a economia neoclássica para justificar o seu liberalismo, os Estados desenvolvimentistas justificam seu papel ativo no desenvolvimento com a teoria econômica keynesiano-estruturalista. Concretamente, eles buscaram proteger e promover sua indústria, no início, por meio de uma estratégia de industrialização por substituição de importações, seguida, desde os anos 1970 no Brasil e México, por uma estratégia baseada na exportação de bens manufaturados.

O Estado desenvolvimentista latino-americano entrou em crise nos anos 1980 não devido a características que lhe eram inerentes, como afirmaram os neoliberais, mas em face a uma grave crise financeira - a grande crise da dívida externa dos anos 1980 - que fragilizou os países latino-americanos e abriu espaço para o consenso de Washington e para a volta do Estado liberal-dependente. Diante da previsível incapacidade deste último de promover, entretanto, a retomada do desenvolvimento, as ideias desenvolvimentistas reemergiram em vários países. Deviam agora dar conta, todavia, de um contexto diferente de restrições internas e externas: muitos dos países já se haviamindustrializado e todos competiam no quadro 
da globalização ${ }^{1}$. Uma estratégia nacional de desenvolvimento continuava, assim, necessária, mas precisava se adaptar aos novos tempos, o que levou economistas e cientistas políticos estruturalistas da região a procurar defini-la e a denominá-la Novo Desenvolvimentismo.

O Estado novo-desenvolvimentista continua a basear-se, conceitualmente, nas ideias estruturalistas e keynesianas, mas agora enriquecidas por um conjunto de novos modelos econômicos que foram desenvolvidos, levando em consideração políticas desenvolvimentistas bem-sucedidas em países asiáticos - enriquecidos, em suma, por uma macroeconomia estruturalista do desenvolvimento ${ }^{2}$. O novo sistema, cuja construção está hoje adiantada, enfatiza os principais preços macroeconômicos (nomeadamente, a taxa de câmbio e a taxa de juros) e coloca a taxa de câmbio no centro da teoria econômica do desenvolvimento. Baseia-se em uma macroeconomia estruturalista do desenvolvimento cujos foros principais têm sido os congressos da Associação Keynesiana Brasileira e do Centro Celso Furtado.

No plano das políticas públicas, os aspectos que definem o Estado novodesenvolvimentista são o papel estratégico do Estado, a prioridade dada ao desenvolvimento econômico, uma taxa de câmbio competitiva, a responsabilidade fiscal e o aumento da carga tributária para financiar os gastos sociais. No plano político, o Estado novo-desenvolvimentista supõe a formação de um pacto político ou coalizão de classes associando empresários, a burocracia pública e a classe trabalhadora, coalizão esta que tem como adversários os capitalistas rentistas, inclusive os proprietários de empresas e concessões públicas monopolistas, os exportadores de commodities e os interesses estrangeiros. O aumento dos gastos sociais é crucial para este Estado, porque, no quadro da democracia, os eleitores exigem do Estado o aumento de gastos em educação, saúde, assistência social e seguridade social.

A questão básica colocada neste trabalho é saber até que ponto nos países de renda média da América Latina, como o Brasil e a Argentina, está surgindo um Estado novo-desenvolvimentista. Em segundo lugar, discutir em que medida as recentes mudanças políticas e econômicas nos países mais pobres como Venezuela, Bolívia e Equador vão na mesma direção ${ }^{3}$.

(1) Para uma discussão a respeito dos países desenvolvimentistas no Leste Asiático e como eles se adaptaram às novas circunstâncias, ver Wong (2004).

(2) Por “Economia Estruturalista do Desenvolvimento", entendem-se as teorias desenvolvidas entre os anos 1940 e 1960 por economistas como Rosenstein-Rodan, Ragnar Nurkse, Gunnar Myrdal, Raul Prebisch, Hans Singer, Arthur Lewis, Celso Furtado e Albert Hirschman.

(3) O termo "Nova Esquerda", usado para descrever políticos e coalizões de esquerda eleitos na América Latina desde 1999, refere-se, geralmente, à Argentina, Bolívia, Brasil, Chile, Equador, Uruguai e Venezuela (ver, por exemplo, os artigos em Natanson (2008) e Arnson et. al (2009). Os autores deste artigo acreditam que "nova esquerda nacionalista" descreve melhor a orientação política desses governos. Haverá maior concentração na análise dos países mencionados no texto, pois lá as mudanças na economia no que se refere à sua competição industrial global foram maiores. 


\section{Contexto político e econômico}

Para superar o subdesenvolvimento, países latino-americanos implementaram políticas desenvolvimentistas no século XX. No Brasil, a industrialização e o desenvolvimento econômico liderado pelo Estado foram a busca de todos os governos entre os anos 1930 e os anos 1970. Getúlio Vargas foi uma figura central na construção do pacto e do Estado desenvolvimentista. Depois dele, o presidente Juscelino Kubitschek continuou no mesmo caminho, embora fazendo uma abertura maior para os investimentos diretos das empresas multinacionais. Durante o regime militar (1964-1984), o pacto desenvolvimentista foi retomado, mas com a exclusão da classe trabalhadora. As práticas e ideologias das diversas administrações naturalmente diferiam entre si. Vargas foi um líder autoritário e nacionalista que promoveu a industrialização e deu um papel aos trabalhadores urbanos no contrato social para o desenvolvimento. As atuais leis trabalhistas brasileiras remetem a essa época. Pode-se dizer que Vargas foi o Bismarck brasileiro. Não era um democrata, mas, observando-se historicamente, país algum fez até hoje sua revolução industrial em um contexto democrático. No Brasil, embora houvesse eleições antes da gestão era Vargas, estas eram marcadas pela fraude e não havia o sufrágio universal ${ }^{4}$. Após o Estado Novo (1937-45), a democracia foi estabelecida, mas o golpe militar de 1964 fez o Brasil retornar ao regime autoritário. A transição para uma democracia consolidada ocorreu apenas em 1985, depois que a revolução capitalista havia sido completada e as eleições diretas para presidente ocorreram novamente apenas em 1989.

O antigo ou nacional-desenvolvimentismo teve duas fases com diferentes objetivos econômicos e sociais. Primeiro, de 1930 até o início da década de 1960, o desenvolvimentismo tinha como objetivo a substituição de importações e foi baseado em um pacto político entre as elites industriais, a nova burocracia pública, trabalhadores urbanos e as elites não exportadoras agrícolas ${ }^{5}$. Segundo, de meados dos anos 1960 até o final da década de 1970, a estratégia de crescimento passou do modelo de substituição de importações ao de exportação de bens manufaturados e excluiu os trabalhadores.

Além das bases sociais e objetivos da coalizão de classe dominante, é preciso considerar uma terceira variável para compreender o Estado desenvolvimentista na América Latina e seu colapso nos anos 1980, isto é, o financiamento externo. A

(4) Apesar de algumas mulheres já terem conseguido votar e elegerem-se antes desta data, o sufrágio feminino foi regulamentado e permitido sem restrições (formais) apenas em 1934. Analfabetos só adquiriram o direito de voto no Brasil em 1988.

(5) As elites exportadoras de produtos agrícolas e minérios geralmente não participam de uma coalizão de classes desenvolvimentista porque se beneficiam de rendas ricardianas que dão origem à Doença Holandesa ou "maldição dos recursos naturais" - uma falha de mercado que sobreaprecia permanentemente a taxa de câmbio. Para tornar a taxa de câmbio competitiva e industrializar-se, o Estado desenvolvimentista taxa direta ou indiretamente a exportação de commodities - algo que as elites agrícolas e de minério não aceitam. 
industrialização só foi possível na região porque, apoiados na teoria estruturalista do desenvolvimento, seus economistas criticaram e seus políticos rejeitaram a lei das vantagens comparativas do comércio internacional. O financiamento externo, ou seja, o financiamento em moeda estrangeira, por meio da qual o Norte imperial dificulta o desenvolvimento dos países da sua periferia, entretanto, não foi criticado. No Brasil, após a crise financeira de 1929, o financiamento externo havia sido suspenso e entre os anos 1930 e 1960, coube à poupança interna financiar o crescimento.Desde meados dos anos 1950, porém, o financiamento externo foi retomado, em primeiro lugar, na forma de investimentos diretos por meio dos quais as empresas multinacionais trataram de assegurar os mercados domésticos de bens manufaturados, previamente fechados a importações e, a partir dos anos 1970, também sob a forma de empréstimos em moeda forte. Aceitar esses empréstimos foi um grave erro, já que os recursos antes financiaram o consumo do que o investimento e nos 1980 transformaram-se na grande crise da dívida externa. Ao contrário do que habitualmente se afirma, a origem dessa crise não foi "o esgotamento do modelo de substituições de importações", mas o financiamento externo. A ortodoxia liberal, por sua vez, logrou tornar hegemônica a ideia de que fora o protecionismo promovido pelo Estado desenvolvimentista a causa principal da crise. Na verdade, o modelo de substituição de importações já se havia esgotado na década de 1960 e países como Brasil e México já estavam buscando um modelo de exportação desde o final dessa década ${ }^{6}$. A principal razão da crise econômica na década de 1980 foi a escolha do financiamento externo. Essa é, por si só, uma política questionável porque existe geralmente uma elevada taxa de substituição da poupança interna pela externa e, porque, ao se endividar em moeda estrangeira, o país fica propenso a crises de balanço de pagamentos. Assim, o que aconteceu em 1979-80 foi: contratos de dívida com taxas de juros flutuantes, mais a decisão do Banco da Reserva Federal dos EUA de aumentar drasticamente a taxa de juros internacional levaram os países altamente endividados da América Latina a uma crise financeira de grandes proporções que, em pouco tempo, se transformou em uma crise fiscal do Estado, já que este, como sempre acontece nas crises financeiras, acabou assumindo as dívidas privadas.

\section{Transições democráticas e crise}

Foi nesse contexto de instabilidade e crise financeira que muitos países latinoamericanos fizeram suas transições de um regime autoritário para a democracia: a Bolívia em 1980, a Argentina em 1983, o Brasil em 1985. A década de 1980 foi

(6) Maria da Conceição Tavares (1963) já havia demosntrado o esgotamento do modelo de substituição de importações do Brasil no início dos anos 1960. Respondendo a esse fato, as exportações brasileiras de produtos manufaturados aumentaram de 6\% das exportações totais em 1965 para mais de $60 \%$ nos anos 1980 . O fechamento do país para a importação de computadores (exemplo sempre usado para demonstrar a persistência do modelo de substituição de importações no Brasil, nos anos 1970 e 1980) existiu e foi um erro, mas a indústria de tecnologia de informações era de menor importância naquela época. 
perdida economicamente, mas uma década de ganhos políticos. A crise da dívida e a inflação elevada facilitaram as transições, pois as coalizões políticas democráticas e desenvolvimentistas podiam atribuir o baixo crescimento e a inflação ao regime militar. Quando, porém, se logrou a transição democrática, a crise não resolvida tornou-se um problema de difícil solução para as novas administrações democráticas. A insolvência externa e a alta inflação foram enfrentadas com políticas econômicas equivocadas, frutos de uma euforia populista causada pela conquista da democracia. Estes fatos, ocorridos especialmente na Argentina e no Brasil agravaram a crise financeira e levaram os países à hiperinflação no final da década de 1980 .

Ao mesmo tempo, nos Estados Unidos e Grã-Bretanha e, em seguida, nos demais países ricos, uma coalizão de classes neoliberal, envolvendo capitalistas rentistas e financistas, tornou-se política e economicamente dominante. Essa dominação tornou-se radical após a queda do Muro de Berlim, em 1989, seguida pelo colapso da União Soviética em 1991. O caminho único traçado pelos Estados Unidos pareceu então ser inquestionável. No Brasil e Argentina, a incapacidade dos novos governos democráticos para enfrentar a grande crise da dívida externa e da alta inflação, minou o apoio social ao Estado desenvolvimentista e, em 1991, com Fernando Collor na presidência do Brasil e com Carlos Menem na Argentina, ambos os países curvaram-se ao consenso neoliberal de Washington - um consenso ao qual o Chile já aderira desde o golpe militar de 1973 e o México desde meados dos anos 1980. No caso do Chile, as consequências desastrosas das políticas e reformas neoliberais manifestaram-se cedo, na grande crise financeira de 1981-82 ${ }^{7}$. Como, no entanto, ainda durante o regime militar, um ministro das finanças mais sensato tenha logrado corrigir as políticas monetaristas equivocadas adotadas pelos Chicago boys e levado o país a crescer ${ }^{8}$, o Chile foi apresentado pelos defensores das ideias mais tarde conhecidas como consenso de Washington, tornando-se o exemplo da superioridade do caminho neoliberal.

Em síntese, os anos 1980 foram tanto os anos da grande crise financeira da dívida externa quanto da redemocratização na América Latina. Foram anos de populismo econômico nas administrações Carlos Alfonsin e José Sarney (1983-89 e 1985-89, na Argentina e no Brasil, respectivamente), assim como já havia sido no México, no governo Lópes Portillo (1976-1982). Os anos 1990 foram os anos neoliberais da América Latina. O México foi o primeiro grande país latino-americano a curvar-se ao neoliberalismo, ainda em 1985, durante o governo Miguel de la Madrid (1982-88). Seu sucessor, Carlos Salinas (1988 -94), levou o país à adesão ao Nafta,

(7) A análise clássica dessa crise, assim como da crise na Argentina, em 1979-80, é a de Carlos DiazAlejandro (1981).

(8) A referência é de Hernán Büchi, ministro das finanças do Chile entre 1985 e 1989. A crise rompeu em 1982, levou à demissão do então ministro e de quatro novos ministros, até que, em fevereiro de 1985, Büchi assumiu a direção da economia chilena. 
o que tornou completa a hegemonia do neoliberalismo nesse país. Na Argentina, o neoliberalismo tornou-se dominante após a hiperinflação de 1989, no governo Carlos Menem (1989-1999). No Brasil, a submissão ao consenso de Washington teve início no governo Fernando Collor de Melo (1990-92). O governo Itamar Franco (1992-94) tentou reverter essa mudança. Em 1994, Fernando Henrique Cardoso, então Ministro da Fazenda, implementou com sucesso o Plano Real - um plano heterodoxo de estabilização de preços que utilizou a teoria da inflação inercial para controlar a inflação que assolava a população desde 1980. Uma vez eleito presidente, entretanto, ele também sucumbiu às ideias neoliberais, exceto na área social onde desenvolveu uma agenda social-democrata. Em sua administração (1995-2002), dois modelos econômicos estavam competindo dentro do próprio governo: o modelo neoliberal e um modelo desenvolvimentista. A corrente neoliberal, que foi dominante, deu prioridade para a estabilização de preços, definiu altas taxas de juros,valorizou o reale não ofereceu incentivos diretos para o setor industrial (Sallum Jr., 1999, p. 33).

A linha de ação oferecia vantagens em curto prazo, mas em médio e longo prazo, seus riscos apareceram: baixo crescimento econômico, aumento do desemprego e vulnerabilidade às perturbações no mercado financeiro internacional. Levou, também, o país à desindustrialização precoce. Um outro grupo dentro do governo defendia uma espécie de liberal-desenvolvimentismo, exigindo a depreciação da moeda, taxas de juros mais baixas e uma menor dependência de capital estrangeiro para equilibrar a balança de pagamentos, mas o presidente não seguiu esta linha de ação. O fraco crescimento econômico no governo FHC e a crise financeira de 1998 facilitaram, então, a eleição de Luiz Inácio Lula da Silva para a presidência em outubro de 2002.

Nos anos 1990, as políticas econômicas neoliberais e as reformas orientadas para o mercado foram comuns a praticamente todos os países latino-americanos. Seus maus resultados econômicos e sociais expressaram-se nas eleições de presidentes nacionalistas e de esquerda na região. Uma nova esquerda nacionalista passou a ser eleita na América Latina, ou seja,na Venezuela, Hugo Chávez elegeu-se presidente em 1999; no Brasil, Luiz Inácio Lula da Silva foi eleito em 2002, seguido por Dilma Rousseff em 2010; na Argentina, Eduardo Duhalde, em 2002, seguido por Néstor Kirchner em 2003 e Cristina Kirchner em 2007 e 2011; na Bolívia, Evo Morales em 2006; no Equador, Rafael Correa em 2007; na Nicarágua, Daniel Ortega em 2007; no Paraguai, Fernando Lugo em 20089; em El Salvador, Mauricio Funes em 2009; no Peru, Ollanta Humala em 2011 ${ }^{10}$. Todos esses presidentes vêm tentando implementar políticas desenvolvimentistas e sociais, sempre com oposição dos liberais locais e dos países ricos.

(9) Já derrubado por um golpe liberal em 2012.

(10) Além destes, Tabaré Vázquez em 2005 no Uruguai (e depois dele em 2010, José Mujica) e Michelle Bachelet em 2006, no Chile. 


\section{Novo desenvolvimentismo como tipo ideal}

Ao mesmo tempo em que estavam sendo eleitos políticos com discursos contra as ideias neoliberais, surgiam também novas ideias a respeito do desenvolvimento e desenvolvimentismo. Em 2003, Bresser-Pereira lançou o conceito de novo desenvolvimentismo, contrapondo-o tanto ao consenso de Washington quanto ao antigo desenvolvimentismo ${ }^{11}$. Logo, um grande grupo de economistas póskeynesianos e estruturalistas juntaram-se a ele e, em 2010, oitenta entre os mais importantes economistas do desenvolvimento no mundo discutiram e aprovaram um documento a respeito das "Dez Teses sobre o Novo Desenvolvimentismo"12. O novo desenvolvimentismo tornava-se, assim, uma estratégia alternativa ao consenso de Washington e ao antigo desenvolvimentismo, uma nova instituição, um conjunto de ideias e normas definidas e compartilhadas.

Serão apresentadas, a seguir, as ideias do novo desenvolvimentismo, contrastando-as com o velho desenvolvimentismo e a ortodoxia liberal, destacandose as diferencas entre suas políticas econômicas as teorias econômicas em que se fundamentam:

Escopo. O antigo desenvolvimentismo era aplicado aos países que estavam começando sua revolução industrial. A ortodoxia liberal pretende ser aplicável a todos os tipos de países. O novo desenvolvimentismo aplica-se a países de renda média que já completaram sua revolução capitalista.

Estado na produção. $\mathrm{O}$ antigo desenvolvimentismo atribuía ao Estado um papel importante na produção. A ortodoxia liberal não lhe atribui papel algum nesta questão. O novo desenvolvimentismo limita um papel ativo do Estado aos setores monopolistas ou quase monopolistas, em especial, aos de infraestrutura, mineração e serviços públicos.

Função estratégica do Estado. Tanto o antigo desenvolvimentismo quanto o novo atribuem um papel estratégico ao Estado na definição, em conjunto com a sociedade, de uma estratégia desenvolvimentista nacional e, em sua implementação. A ortodoxia liberal limita o papel do Estado a garantir os direitos de propriedade e os contratos e a de defesa da concorrência.

Planejamento. $\mathrm{O}$ antigo desenvolvimentismo atribuía um papel fundamental ao planejamento econômico. A ortodoxia liberal rejeita-o. O novo desenvolvimentismo divide a economia em setor competitivo e em setor monopolista (os setores de infraestrutura, serviços públicos, indústria de base e grande mineração) e quer o planejamento apenas para o setor monopolista aos primeiros, basta o acompanhamento de seu desenvolvimento.

(11) Para um relato do surgimento do novo desenvolvimentismo e da macroeconomia estruturalista do desenvolvimento, ver Bresser-Pereira (2011).

(12) Consultar o site disponível em: <www.tenthesesonnewdevelopmentalism.org>. Acesso em: 11 set. 2012. 
Responsabilidade fiscal. O antigo, o novo desenvolvimentismo e a ortodoxia liberal recomendam déficits orçamentários limitados para os momentos de crise. Os três defendem, portanto, a responsabilidade fiscal, mas, enquanto os desenvolvimentistas estão sempre ameaçados por uma visão vulgar do keynesianismo que recomenda o aumento da despesa pública para quase todas as dificuldades, a ortodoxia liberal está ameaçada por uma visão também vulgar, a qual recomenda corte da despesa pública como uma espécie de panaceia.

Taxa de juros e taxa de câmbio. $O$ antigo desenvolvimentismo dava pouca atenção à taxa de juros e à taxa de câmbio ou à formulação de políticas macroeconômicas e enfatizava a política industrial (cujo escopo era suficientemente amplo para incluir questões macroeconômicas como o da taxa de câmbio efetiva determinada por tarifas de importação e subsídios de exportação). A ortodoxia liberal também não presta atenção a esses preços macroeconômicos porque supõe serem corretamente determinados pelo mercado. O novo desenvolvimentismo rejeita tal suposição e afirma que, nos países em desenvolvimento, a taxa de juros tende a ser muito alta e a taxa de câmbio, cíclica e cronicamente sobrevalorizada. A taxa de juros costuma ser alta porque é usada com abuso para controlar a inflação e combater a "repressão financeira" que juros baixos representariam. A taxa de câmbio também se inclina a ser sobreapreciada devido à doença holandesa e às entradas excessivas de capitais causadas pela taxa de juros alta, política de crescimento com poupança externa, uso da taxa de câmbio como âncora cambial e populismo cambial (a prática adotada por muitos políticos de fixar a taxa de câmbio o que, no curto prazo, irá reduzir a inflação, aumentar artificialmente os salários e facilitar a sua reeleição).

Doença holandesa. O antigo desenvolvimentismo tinha uma intuição da doença holandesa e procurava neutralizá-la por meio de regimes de taxa de câmbio múltiplo, ou então, de combinação de tarifas de importação e subsídios de exportação. A ortodoxia liberal a ignora. O novo desenvolvimentismo, por sua vez, define com clareza a doença holandesa, vendo-a como uma sobreapreciação permanente da taxa de câmbio causada por rendas ricardianas que tornam viável a exportação de commodities a uma taxa de câmbio substancialmente mais apreciada comparada àquela necessária para as demais empresas produtoras de bens comercializáveis serem competitivas.

Wage-led $\mathrm{x}$ export-led (desenvolvimento puxado pelos salários ou exportações. O desenvolvimento é wage-led quando prevalece a industrialização substitutiva de importações, o coeficiente de importações é cadente e os salários aumentam mais do que os lucros. É profit-led quando as exportações e o coeficiente de importações (e de exportações) aumentam e os lucros aumentam mais do que os salários. O desenvolvimento é equilibrado quando PIB e exportações, salários e lucros crescem aproximadamente à mesma taxa. $\mathrm{O}$ antigo desenvolvimentismo não acreditava na possibilidade de países em desenvolvimento exportarem bens 
manufaturados. Defendia a substituição de importações que, por definição, implicava redução do coeficiente de importações e desenvolvimento voltado ao mercado interno. Defendia, portanto, um desenvolvimento puxado pelos salários. A ortodoxia liberal ignora a discussão e afirma que a lei das vantagens comparativas do comércio internacional determinará o modelo de crescimento. O novo desenvolvimentismo supõe estar a estratégia de substituição de importações esgotada há muito para países de renda média e que o coeficiente de importações deve ser razoavelmente constante. Assim, se a taxa de crescimento for considerada satisfatória, o desenvolvimento não deve ser nem wage-led nem profit ou export-led, mas equilibrado. Apenas se for necessário corrigir a taxa de câmbio e aumentar a taxa de investimento, o desenvolvimento deverá ser temporariamente profit-led ${ }^{13}$.

Taxa de câmbio competitiva. $O$ antigo desenvolvimentismo não prestava atenção à necessidade de uma taxa de câmbio competitiva porque estava voltado para o mercado interno. A ortodoxia liberal supõe que a taxa de câmbio determinada pelo mercado é normalmente competitiva. O novo desenvolvimentismo afirma que o mercado, se funciona bem, tende a levar a taxa de câmbio para o equilíbrio corrente (aquele que equilibra intertemporalmente a conta-corrente do país), mas, quando há doença holandesa, a verdadeira taxa de câmbio de equilíbrio, a taxa competitiva, é a de "equilíbrio industrial" - a taxa de câmbio que torna competitivos setores de bens comercializáveis utilizando tecnologia no estado da arte mundial.

Inflação. $O$ antigo desenvolvimentismo adotava a teoria da inflação estrutural, baseada em gargalos de oferta e aceitava uma inflação de até $20 \%$ ao ano. A ortodoxia liberal não vê razão para os países em desenvolvimento apresentarem taxas de inflação acima dos padrões internacionais. O novo desenvolvimentismo concorda com isso se o país já é um país de renda média, pois, neste caso, os gargalos de abastecimento já deixaram de ser relevantes.

Proteção $\mathbf{x}$ taxa de câmbio. $\mathrm{O}$ antigo desenvolvimentismo defendia tarifas alfandegárias altas e taxas de câmbio múltiplas a fim de proteger as indústrias que assumiam serem "indústrias nascentes". A ortodoxia liberal rejeita qualquer tipo de proteção. O novo desenvolvimentismo supõe que a indústria de transformação de países de renda média não é mais infante e não vê razão para a proteção, mas exige uma taxa de câmbio competitiva.

Restrição externa e poupança externa. $O$ antigo desenvolvimentismo acreditava na existência de uma restrição estrutural externa para o crescimento econômico - uma escassez permanente de dólares ou outras moedas de reserva que decorreria de uma elasticidade-renda da demanda de bens industriais maior do que um, enquanto a elasticidade-renda de bens primários nos países ricos é menor do

(13) Num estado de equilíbrio em que a taxa de investimentos e a taxa de lucro são vistas como satisfatórias na sociedade, salários, lucros e exportacões crescerão de forma quase igual, enquanto a taxa de câmbio é mantida competitiva. Somente quando for necessário depreciar a taxa de câmbio, exportacões e lucros crescerão mais rapidamente que os salários por algum tempo, antes que estes últimos voltem a crescer de forma mais acelerada. 
que um. Assim, defendia o crescimento com poupança externa. A ortodoxia liberal fortemente apoia tal tese, porque a interessa, por um lado, que haja déficit em contacorrente crônico, portanto câmbio cronicamente sobreapreciado e, por outro lado, que os países em desenvolvimento sejam financiados por meio de empréstimos e investimentos diretos. O novo desenvolvimentismo afirma que o problema das elasticidades nunca foi fundamental e perde importância à medida que o país passa a exportar produtos manufaturados: a restrição ou escassez crônica de dólares só existe porque a taxa de câmbio tende a ser cronicamente sobreapreciada nos países em desenvolvimento. O novo desenvolvimentismo critica, portanto, a política de crescimento com poupança externa, argumentando que ocorre geralmente uma alta taxa de substituição da poupança interna pela externa e sublinha o risco permanente de crises cambiais envolvido. Quer, portanto, uma estratégia de crescimento com base em financiamento nacional, poupança interna e equilíbrio ou (no caso de doença holandesa) superávit em conta-corrente.

Taxa de câmbio fixa ou flutuante. $\mathrm{O}$ antigo desenvolvimentismo aceitava o regime de taxa de câmbio fixa definido em Bretton Woods e defendido por Keynes. A ortodoxia liberal pede of free float que, supostamente, acabaria com a possibilidade de crises financeiras. O novo desenvolvimentismo rejeita a rígida alternativa " $f i x$ or float" e, com base na tendência à sobreapreciação cíclica da taxa de câmbio, quer uma taxa de câmbio flutuante fortemente administrada. Para isso, recomenda a compra e venda de reservas, os controles de capital e, para neutralizar a doença holandesa, um imposto variável sobre as exportações dos produtos que a originam - imposto igual à diferença entre a taxa de câmbio de equilíbrio industrial e a de equilíbrio corrente que, ao deslocar a curva de oferta do bem em relação à taxa de câmbio, leva a taxa de câmbio para o equilíbrio industrial.

Desenvolvimento social. $\mathrm{O}$ antigo desenvolvimentismo era geralmente parte de uma estratégia de desenvolvimento de um regime autoritário que estava envolvido na revolução nacional e industrial do país. Defendia uma melhor distribuição de renda, mas não tinha uma política de bem-estar social. A ortodoxia liberal está apenas preocupada com o livre comércio supondo que o mercado cuidará do resto. O novo desenvolvimentismo geralmente é implementado em novas democracias e pretende ser também um desenvolvimentismo "social" - um desenvolvimentismo que também está preocupado com a distribuição mais igualitária de benefícios na sociedade.

Fundamentação teórica. Ao se fazer tal comparação tríplice, não foi distinguido entre o novo desenvolvimentismo, entendido apenas como conjunto de políticas que forma uma estratégia nacional de desenvolvimento e a teoria em elaboração em que ele se baseia, a Macroeconomia Estruturalista do Desenvolvimento. Esta, por sua vez, baseia-se na teoria estruturalista do desenvolvimento e na macroeconomia keynesiana, mas procura dar um passo adiante em relação a elas, levando em consideração a realidade atual das economias modernas. 
O novo desenvolvimentismo não é apenas uma lista de políticas. É uma estratégia de desenvolvimento nacional informal. É a instituição fundamental para o desenvolvimento econômico, a soma de valores, objetivos, políticas, leis e, principalmente, entendimentos e compromissos que criam boas oportunidades de investimento para os empresários e melhoram o padrão de vida da população, fruto de uma coalizão de classes ou um pacto político desenvolvimentista. Algum tipo de consenso em uma sociedade sobre as políticas que são escolhidas é essencial para o bom funcionamento do sistema político e econômico. Quando tais políticas e as ideias que as sustentam não são impostas pela força, mas adotadas livremente pela sociedade, pode-se assumir que (apesar dos problemas comuns de representação ou agência) existe um acordo social ou um pacto político desenvolvimentista. Nas democracias, a implementação do novo desenvolvimentismo implica que o governo conte com o apoio do povo e de parte das elites - um amplo apoio ligando as classes sociais.

Em nenhum país existe de forma pura apenas um dos três tipos ideais de estratégias de desenvolvimento descritos acima. Ademais, governos muitas vezes adotam políticas incompetentes ou irresponsáveis, independentemente do fato de serem guiados por economistas antigo-desenvolvimentistas, liberal-ortodoxos ou novo-desenvolvimentistas. O que se pretende demonstrar aqui, porém, é que, quando existe um acordo social desenvolvimentista e a nação adota uma estratégia desenvolvimentista a qual se aproxima da esboçada acima, tal nação está construindo um Estado novo-desenvolvimentista e realizando seu desenvolvimento

A existência de um acordo social, porém, não significa completo consenso. As elites liberais e dependentes e os interesses externos continuarão opondo-se ao papel estratégico desempenhado pelo Estado na regulação do mercado e no estímulo ao desenvolvimento econômico, social e ambiental dos países em desenvolvimento. O acordo desenvolvimentista dentro da coalizão de classes também não é, necessariamente, permanente. Ele precisa ser constantemente reconstruído, pois a possibilidade de que ele se desfaça ou rache está sempre presente. Quando isso acontece, abre-se espaço para a luta de classes, a dominação liberal e a repressão social.

O Estado novo-desenvolvimentista é uma forma de Estado adaptado ao capitalismo global, a um estágio do capitalismo onde a competição econômica entre as nações é fundamental. O papel do Estado, nesse caso, é criar oportunidades de investimento, investir ele mesmo quando necessário e regular os mercados, os financeiros em particular, para assegurar o crescimento com estabilidade de preços e a estabilidade financeira. O desenvolvimento para os novos-desenvolvimentistas é visto não só como crescimento econômico e da industrialização, mas também como a redução das desigualdades sociais e melhoria no padrão de vida da população. 
O objetivo econômico dos países de renda média é de alcançar o nível de bem-estar dos países ricos. Enquanto a estratégia liberal-ortodoxa raramente é compatível com o crescimento a longo prazo, a estratégia novo-desenvolvimentista é um caminho para esse objetivo, mas não o assegura. A probabilidade que tenha êxito será tanto maior quanto mais desenvolvido já for o país pois, assim, já contam com uma sociedade e um Estado melhor estruturados. Os países de renda média enfrentam algumas dificuldades em serem governados, mas, para os países mais pobres, essas dificuldades são maiores. Um Estado novo-desenvolvimentista não tem necessariamente de seguir todas as políticas aqui apresentadas - estas podem ser pensadas como um tipo ideal -, mas deve ter uma estratégia de desenvolvimento nacional apoiada por uma coalizão política desenvolvimentista. Tal Estado tem um papel estratégico no investimento e no planejamento de setores monopolistas, na política macroeconômica - em particular em relação à taxa de câmbio - na regulação dos mercados financeiros e nas políticas sociais ou distributivas voltadas para construir um Estado que, além de desenvolvimentista, seja de bem-estar social.

\section{Estados novo-desenvolvimentistas na América Latina?}

Pode-se dizer, então, que o Estado desenvolvimentista está de volta na América Latina e o mesmo tenta ser um Estado de bem-estar social? Conforme acentua Vera Cepeda (2012), o novo desenvolvimentismo está já hoje presente no Brasil e caracteriza-se pela prioridade à inclusão social. Será que se pode afirmar isto? Para responder a estas perguntas à luz dos argumentos e definições acima apresentados, é preciso examinar as recentes políticas relativas ao papel do Estado, à política macroeconômica e à política social nos países em análise. Como o novo desenvolvimentismo foi pensado considerando países de renda média, haverá uma abordagem mais específica ao Brasil e à Argentina, além de três países mais pobres ou pré-industriais onde a esquerda nacionalista avançou e tenta implementar políticas desenvolvimentistas: Bolívia, Equador e Venezuela.

Na Argentina, o presidente Duhalde (2002/2003) fez escolhas desenvolvimentistas com o seu ministro da Economia Roberto Lavagna, que serviu também sob Néstor Kirchner até 2005. O governo argentino enfrentou interesses do Norte, reestruturou a dívida externa de forma corajosa e bem-sucedida, desvalorizou o peso e manteve-o desvalorizado ao mesmo tempo em que manteve o equilíbrio fiscal, de forma que alcançou superávit em conta-corrente e fiscal. Néstor e Cristina Kirchner tentaram manter esse rumo e adotaram uma política de intervenção econômica crescente por parte do Estado. Um exemplo foi a renacionalização de parte majoritária da companhia petrolífera Repsol $\mathrm{YPF}^{14}$ que a Câmara dos

(14) A empresa argentina Yacimientos Petroliferos Fiscales YPF foi fundada em 1922 como primeira companhia petrolífera exclusivamente estatal no mundo. Nos anos 1990, iniciou-se sua privatização. Em 1999, a companhia espanhola Repsol adquiriu 98\% de suas ações, vendidas parcialmente a outros grupos, mais tarde. O processo de renacionalização de 51\% da empresa deu-se no governo Cristina Kirchner, em 2012. 
Deputados da Argentina aprovou com uma grande maioria em maio de 2012. Embora a presidente tenha sido criticada por seu estilo ao agir sem prévia negociação com a empresa, as pesquisas de opinião mostraram que a decisão teve apoio da população. O novo desenvolvimentismo, por sua vez, expressou-se na Argentina de maneira bem-sucedida no fato que o país logrou neutralizar sua doença holandesa e manter a taxa de câmbio competitiva. Além das taxas elevadas de crescimento que de muito superaram a mera reposição das perdas durante a crise, o sinal dessa realização foi superávit em conta-corrente. $\mathrm{O}$ fato de ele ter sido mantido indicava que a taxa de câmbio continuava razoavelmente competitiva. Após uma década de redução da participação no produto interno bruto (PIB) nos anos 1990, a indústria argentina recuperou-se na década de 2000: a parcela da indústria, de 32,7\% do PIB em 1991, havia caído para 26,6\% em 2001, mas voltou para 30,9\% do PIB em $2010^{15}$. O nível de pobreza, de 6,7\% em 1992 e com aumento para 25,8\% em 2002 após a crise, caiu para o nível sem precedentes de $3,9 \%$ em $2009^{16}$. É verdade que, como no Brasil, o aumento dos preços das commodities contribuiu para a aceleração do crescimento. Mais recentemente, porém, o governo cometeu erros graves, como o de manipular os índices de inflação e de tentar controlar a inflação por meio da apreciação cambial - algo que o Brasil também fez durante o governo Lula. Em consequência, a taxa de câmbio aos poucos se apreciou e os superávits em conta-corrente aproximaram-se de zero. Repetiram-se, assim, velhos erros desenvolvimentistas.

No Brasil, o presidente Lula tentou construir um acordo social para o desenvolvimento, envolvendo trabalhadores, empresários, lideranças sociais e a burocracia estatal. A criação do Conselho de Desenvolvimento Econômico e Social (CDES) foi a iniciativa formal nesse sentido. A adoção de uma política industrial mais ativa, o fortalecimento do Banco Nacional de Desenvolvimento Econômico e Social (BNDES) e a retomada das políticas de apoio às empresas nacionais foram claramente políticas desenvolvimentistas. O mesmo pode ser dito da decisão de criar o Programa de Aceleração do Crescimento (PAC). O governo Lula, no entanto, foi incapaz de enfrentar o problema das altas taxas de juros e da taxa de câmbio sobreapreciada. Lula assumiu o governo em meio a uma crise financeira que levara a taxa de câmbio para $\mathrm{R} \$ 3,95$ por dólar e, durante todo o seu governo, essa taxa não deixou de apreciar-se, confirmando a tendência à sobreapreciação cíclica da taxa de câmbio. Ao encerrar seu mandato, a taxa de câmbio estava em R \$ 1,65 por dólar - uma taxa incompatível para que o país continuasse a desenvolver-se de forma economicamente sustentável, fortalecendo sua indústria de produtos manufaturados.O crescimento econômico foi satisfatório e superávits em conta-corrente materializaram-se nos primeiros

(15) Dados do Banco Mundial (World Development Indicators) compilados pela Comissão Europeia (2010)..

(16) Dados da Cepalstat, população que vive com menos que US\$ 2 (2 dólares americanos) por dia. Disponível em: http://websie.eclac.cl/sisgen/ConsultaIntegradaFlashProc.asp\#. Acesso em: 15 jun. 2012. 
anos do governo Lula, mas isso se deveu, principalmente, a um forte aumento dos preços das commodities combinada com competentes políticas distributivas. A diminuição da desigualdade econômica ocorreu, sobretudo, devido ao aumento real do salário mínimo de 54\%, o que garantiu uma demanda doméstica para a indústria de transformação. Dado o fato de que a taxa de crescimento praticamente dobrou no governo Lula, vários antigos desenvolvimentistas interpretaram tal fato como um sinal de um crescimento wage-led e rejeitaram as teses novo-desenvolvimentistas. Logo, porém, o mercado doméstico também foi abastecido por importações e, no último ano do governo Lula, a indústria de transformação voltou a entrar em crise. O país havia aumentado o mercado interno, mas, em seguida, devido ao câmbio sobreapreciado, entregou-o aos países concorrentes, em particular à China. A grande realização de Lula, além do aumento do salário mínimo, foi a redução da pobreza apor meio de programas de transferência de renda. Assim, a taxa de pobreza absoluta que, entre 1992 e 2002, variava entre 28 e $31 \%$ da população, caiu para 24,8\% em 2005 e para $14,2 \%$ em $2009{ }^{17}$. O governo não chegou a ser novo-desenvolvimentista do ponto de vista macroeconômico, mas o foi na política industrial e na política social.

A presidente Dilma Rousseff, ao contrário de seu antecessor, reconheceu os obstáculos centrais ao desenvolvimento econômico brasileiro apontado pela macroeconomia estruturalista do desenvolvimento: a taxa de juros muito superior à internacional e a taxa de câmbio cronicamente sobreapreciada. Apoiada por um presidente do Banco Central identificado com os interesses nacionais, ela liderou uma nova política macroeconômica baseada na solução desses problemas. Hoje, o Brasil está no caminho novo-desenvolvimentista também na área macroeconômica, mas o governo continua incapaz de taxar a exportação de commodities - uma condição para a neutralização da doença holandesa e a obtenção de altas taxas de crescimento. Tal fato mostra a dificuldade que o governo enfrenta na condução de um novo acordo desenvolvimentista, a qual provém da relativa dependência e fragilidade da burguesia nacional industrial (enfraquecida pela desindustrialização e desnacionalização nos anos neoliberais) e da força de uma nova e moderna burguesia agrícola apoiada ideologicamente pelo neoliberalismo.

Na Venezuela, Bolívia e Equador, os outros países latino-americanos em que surgiu uma nova esquerda com traços desenvolvimentistas, a situação é mais difícil. Esses países e seus respectivos governos são nacionalistas, implementaram algumas políticas desenvolvimentistas.Tentam combinar crescimento com distribuição e nacionalizaram algumas empresas privadas (principalmente as indústrias de petróleo e serviços públicos), mas seu ponto de partida é muito diferente dos países de renda média.

(17)Dados da Cepalstat, população que vive com menos que US\$ 2 (2 dólares americanos) por dia. Disponível em: http://websie.eclac.cl/sisgen/ConsultaIntegradaFlashProc.asp\#.. Acesso em: 15 jun. 2012. 
Na Venezuela, a economia depende, em especial, da indústria do petróleo. A pobreza, em termos gerais semelhante ao Brasil, aumentou durante a greve do setor petrolífero e a crise política e econômica de 2002/2003 (40\% da população vivia com menos de US\$ 2 por dia em $2003^{18}$. O governo, todavia, aumentou massivamente os gastos sociais, em particular, referente aos cuidados com a saúde, alimentos subsidiados e educação. O gasto social total aumentou de 8,2\% do PIB em 1998 para 13,6\% em 2006, sem considerar os gastos sociais da estatal petrolífera Petróleos de Venezuela, S.A. (PDVSA), que contribuiu com 7,2\% do PIB para projetos sociais no mesmo ano. O crescimento econômico satisfatório desde 2004 foi, ao contrário do que poderia se pensar, devido principalmente ao setor não-petrolífero, o que aponta para políticas que buscam reduzir a dependência de produtos primários. A Venezuela tem aproveitado o aumento das receitas do petróleo para reduzir sua dívida pública, especialmente, da dívida pública externa, de acordo com Weisbrot e Sandoval (2008). A inflação, no entanto, ainda é alta e a taxa de câmbio continua sobreapreciada significando que a doença holandesa não foi neutralizada.

Na Bolívia, há enormes problemas de dependência de bens primários, além de altas taxas de pobreza (ainda em 32\% da população, vivendo com menos de EUA \$2 por dia em 2007 Políticas desenvolvimentistas do presidente Morales incluíram a nacionalização dos setores de exportação que exploram recursos naturais. Os fundos de pensão privados foram estatizados e o sistema pensões do Estado foi estendido a milhões de bolivianos pobres. A balança comercial mudou de déficit para superávit desde 2003. Ao contrário do que aconteceu no Brasil e na Venezuela, os gastos sociais do governo aumentaram apenas ligeiramente (Weisbrot et al., 2009).

A economia do Equador também se baseia na exportação de bens primários, como bananas, flores, camarão e petróleo. A participação da indústria no PIB foi de $38 \%$ em 2010, mas com uma participação de apenas $10 \%$ da indústria de manufaturados. A pobreza extrema foi reduzida de 31,4\% em 2003 para 19,6\% em 2009. Uma nova Constituição deu mais autonomia ao governo nacionalista, mas este não logrou reverter a dolarização da economia equatoriana, nem a dependência da economia equatoriana dos recursos naturais. Logrou apenas um certo aumento do controle estatal sobre a atividade petrolífera e algum aumento da eficiência da companhia estatal de petróleo.

Para definir o tipo de Estado de um país, é preciso olhar para a organização de seu sistema econômico, os objetivos e a força da coalizão de apoio social e político e para o financiamento do desenvolvimento. Os últimos países mencionados estão tentando ser desenvolvimentistas, mas são pobres e ainda não completaram a revolução industrial. Significa que a apropriação do excedente econômico ainda depende do controle direto do Estado. Tais países apresentam democracias não consolidadas, pois ainda são economicamente fracos e dependentes das exportações

(18) Idem. 
de commodities, com doença holandesa e entrada excessiva de capitais que mantêm sua taxa de câmbio sobreapreciada de forma cíclica e crônica. Coalizões de classe desenvolvimentistas são mais difíceis de ocorrer nesses países, onde interesses divergem radicalmente entre, por um lado, os grupos orientados para a exportação e os rentistas e, por outro lado, os interesses dos trabalhadores e camponeses, da burocracia pública e de uma burguesia industrial incipiente. Assim, fica muito difícil aos governos desempenharem um papel de representante da coalizão desenvolvimentista e, ao mesmo tempo, mediador dos interesses em conflitos. Não existe um interesse comum nacional claro que se identifique com a industrialização. Sem contar com o apoio político necessário das frações de classe dominantes (principalmente dos empresários industriais) e sem a respectiva base industrial, os líderes populares de esquerda desses países enfrentam enormes dificuldades para governá-los.

Conclui-se, assim, haver um retorno do desenvolvimentismo na América Latina, sendo este de qualidades diversas. Países de renda média como o Brasil e a Argentina estão procurando redefinir seu projeto nacional de desenvolvimento, estão procurando adotar políticas econômicas e sociais identificadas com o novo desenvolvimentismo. Estãoprocurando construir um Estado novo-desenvolvimentista e social e um Estado republicano ou capaz, isto é, um Estado capaz de se defender daqueles que tentam capturá-lo para fins particularistas, capaz de realizar reformas institucionais e capaz de adotar políticas macroeconômicas que levem ao alcançamento do padrão de vida dos países ricos. Construir um Estado capaz de promover o acordo social e diminuir as desigualdades. Os países mais pobres, sem uma base industrial, estão tentando também adotar políticas novo-desenvolvimentistas, mas suas chances de sucesso são relativamente baixas devido à clássica armadilha da pobreza que enfrentam: os baixos níveis de educação, as dificuldades para se chegar a um acordo social amplo devido à grande distância entre o povo e as elites e a disposição das elites tradicionais para derrubar governos progressistas na primeira oportunidade que aparece para, assim, recapturarem o Estado. Isso, somado à dificuldade de se financiar investimentos com poupança interna, torna difícil governar tais países. Para países em tais condições, o populismo político - o contato direto do chefe do Estado desenvolvimentista com as massas sem a intermediação dos partidos políticos e das ideologias - é uma alternativa para alcançar o desenvolvimento, porque as massas dão-lhe legitimidade política. O populismo político é, apesar de seus perigos, uma via de inclusão dos pobres na política. Quando, no entanto, o populismo político transmuda-se em populismo econômico, ou seja, em déficits públicos e déficits em conta-corrente irresponsáveis, ele leva a graves problemas macroeconômicos. Hoje, este não é um problema central para os países mais pobres já discutidos no artigo - a Venezuela, a Bolívia e o Equador. Seus líderes reconheceram que a poupança externa, estimulada pela ortodoxia liberal, leva a déficits em conta-corrente e, assim, buscam alternativas a esta via. O problema interno central que enfrentam estes governos 
são as dififuldades provenientes de sua cultura política e instituições, assim como a oposição das elites liberais locais associadas aos países ricos, pois ambos veem no nacionalismo econômico do Estado novo-desenvolvimentista uma ameaça a seus interesses.

\section{Referências bibliográficas}

ARNSON, C. J. et. al, (Org.). La 'nueva izquierda'. In: AMÉRICA Latina: derechos humanos, participación política y sociedad civil. Washington: Woodrow Wilson Center, 2009.

BRESSER-PEREIRA, C. An account of new developmentalism and its structuralist macroeconomics. Brazilian Journal of Political Economy, v. 31, n. 3, p. 493-502, 2011.

CEPEDA, V. Inclusão, democracia e novo-desenvolvimentismo: um balanço histórico. Estudos Avançados, v. 26, n. 75, p. 77-90, maio/ago. 2012.

CONGRESSO NACIONAL DO BRASIL. Constituição da República Federativa do Brasil de 1988. 1988. Disponível em: www.planalto.gov.br/ccivil_03/constituicao/constituicao. htm. Acesso em: 15 jun. 2012.

DIAZ-ALEJANDRO, C. Southern Cone estabilization plans. In: CLINE, W.; WEINTRAUB, S. (Org.). Economic stabilization in developing countries. Washington: The Brookins Institution, 1981. p. 119-148.

FERNANDES, N. A geração ISEB. In: HISTÓRIA e geografia fluminense. Rio de Janeiro: IHGRJ, 2008, p. 457-462 Disponível em: http://grupohistoriadobrasil.blogspot.com. br/2011/05/geracao-iseb.html. Acesso em: 14 set. 2012.

LEVINE, D. H. The transition to democracy: are there lessons from Venezuela? Bulletin of Latin American Research, v. 4, n. 2, p. 47-61, 1985.

NATANSON, J. (Org.). La nueva izquierda. Buenos Aires: Debate, 2008.

SALLUM JR., B. O Brasil sob Cardoso: neoliberalismo e desenvolvimentismo. Tempo Social, v. 11, n. 2, p. 23-47, 1999.

Globalização e estratégia para o desenvolvimento: o Brasil nos anos 90. In: DINES, A. et. al. Sociedade e Estado: superando fronteiras. São Paulo: Edições Fundap, 1998.

TAVARES, Maria da Conceição. Auge e declínio do processo de substituição de importações no Brasil. In: TAVARES, M. C. Da substituição de importações ao capitalismo financeiro. Rio de Janeiro: Zahar Editores, 1972. Original em espanhol, 1963.

WEISBROT, M.; RAY, R.; JOHNSTON, J. Bolivia: the economy during the Morales administration. Center for Economic and Policy Research, Dec. 2009, 4.

; SANDOVAL, L. Update: the Venezuelan economy in the Chávez years. Center for Economic and Policy Research, Feb. 2008, 2.

WONG, J. The adaptive developmental State in East Asia. Journal of East Asian Studies, 4, p. 345-362, 2004. 